\title{
DISPOSAL OF INDUSTRIAL WASTES AND STREAM POLLUTION.*
}

\author{
BY \\ C. A. EMERSON, JR. \\ Chief Engineer Pennsylvania Department of Health.
}

Proper methods for disposal of industrial wastes, which consist of liquids contaminated by the process of manufacture, are essential for prevention of stream pollution or stream despoliation.

Official action to control the discharge of these wastes has not been taken in most instances until after nuisance conditions have arisen or damage has been done to lower riparian owners.

Several general reasons may be advanced for this disregard of public rights by owners of industries and apparent lethargy on the part of government officials; an unfortunate lack of appreciation of the damage to be caused by discharge of the various kinds of industrial waste; former ignorance as to economical and effective methods of treatment; reluctance to make expenditures for installation and maintenance of treatment works when such expenditure might seriously affect the profits of the industry and lastlywant of uniform and definite control legislation.

The result of this delay is particularly noticeable in an industrial State such as Pennsylvania. Even now many of our large streams are so grossly polluted by industrial wastes that their return to a condition of reasonable cleanliness is a task of great proportions, but one which is by no means insurmountable.

The cost of treatment of industrial wastes to prevent stream pollution should undoubtedly be borne by the industries responsible for the discharge. Unfortunately the majority of these wastes are refractory and many of the treatment processes are expensive and relatively inefficient. The enactment of rigid control legislation is only a portion of the remedy and might easily place such a burden upon the industries as to seriously disturb the prosperity of the State. Economical and effective methods of treatment must be developed and proven by actual plant operation before we are ready for stringent legislation.

* Presented at a meeting of the Mechanical and Engineering Section held Thursday, March 3, I921. 
The owners of the industries, as a rule, recognize their moral responsibility and are ready to install treatment processes when it can be shown that there is reasonable assurance of success at a not prohibitive cost.

Methods of treatment which have been developed in the past have oftentimes been unsatisfactory either because of the expense of the treatment process or else because of misconception of the character and degree of treatment required.

There was formerly a tendency to believe that most industrial wastes could be given treatment of the same general character and that all processes should be carried to such a degree of refinement that the effluent discharged into the stream would be clear, colorless, tasteless and free from chemical and bacterial poisons. The judgment of to-day is upon a more rational basis and takes into consideration the great variation in the physical and chemical composition of the different wastes requiring special treatment processes; the relative values of the industries to the State; the present uses and probable future development of the water course and the ability of the stream to absorb and purify the waste by natural agencies.

Another forward step has been the realization that many of our industrial wastes contain matters of value and that improved methods of manufacture which make fuller and better use of the raw materials not only lessen the cost of the commercial product of the industry but reduce or even entirely remove a portion of the objectionable characteristics of the industrial waste, thus simplifying the methods and lowering the cost of treatment.

To secure the desired results requires joint investigations by engineers and chemists, backed by the coöperation of the manufacturers, and preferably under the guidance of the State, for the benefits derived react on the prosperity of the entire Commonwealth.

These principles can well be illustrated by considering methods of treatment now in use or in process of development for some of the more common industrial wastes.

You are doubtless familiar with the objectionable appearing and nuisance producing wastes from tanneries. These wastes have been studied for years, and the development from the first crude settling basins, installed and then promptly neglected, is interesting. Tannery waste carries much matter in suspension; may be alternately acid and alkaline in reaction; is objectionable in color and 
because of its avidity for oxygen and its active chemical constituents will cause a nuisance when discharged into a small stream. In line with the principle of conservation, it has been found that the spent tan liquors discharged from the vats can be concentrated by evaporation and again used in the tanning process. Much of the hair from the hides, which was formerly wasted, is now being reclaimed by flotation combined with fine screening, and has a ready market. The waste from the lime vats is settled in properly designed and carefully operated sedimentation basins, and the sludge is either dried or is dried and also recalcined and used as a fertilizer. The bits of flesh scraped from the inside surface of the hides are used by glue manufacturers. After the removal of these various objectionable constituents, the liquid waste remaining can oftentimes be discharged into a city sewer system or into a large stream without causing nuisance, or if the receiving body of water is so small or its uses are such that further treatment is required, the liquids can be subjected to precipitation by chemicals or the organic matter oxidized through violent agitation by compressed air and subsequently removed by sedimentation. The resulting effluent is free from objectionable color and is sufficiently stable to prevent the creation of a nuisance when discharged into a small stream.

Disposal of the liquid wastes from wool scouring plants, without creation of a nuisance in streams, has been furthered by development of processes for recovery of the grease removed from the wool in the cleaning process. Formerly the grease was recovered by treating the wastes with either naphtha or sulphuric acid, but recently centrifugal separators have been installed, similar in principle to those used in dairies for separating cream from milk, and are operating with marked success. The results obtained at one of the wool scouring establishments in the vicinity of Philadelphia may be taken as an illustration. The total liquid wastes of the plant amount to approximately io,0oo gallons daily. Of this volume, about 7000 gallons are contaminated with grease from the wool and are passed through the separators, yielding from I 80 to 200 pounds of wool grease or crude lanoline a day, which is sold to the refiners at a price representing a desirable profit over the cost of operating the separators. Of equal importance to the sanitarian, the liquid wastes after removal of the grease, are susceptible of treatment by sedimentation and sand filtration at a moderate cost. 
The wastes from the tar'separators, the ammonia, benzol and naphthalene stills of by-product coke ovens and the wastes from gas works employing the water gas method of production, while not ordinarily polluting streams to a sufficient degree to cause objectionable conditions to those residing along the banks, are of particular importance because of the disagreeable tastes which these wastes impart to the water when used for domestic purposes. The types of water filtration plants in general use by municipalities will not remove the disagreeable tastes from a raw water contaminated by these wastes or by the products caused by the chemical combination of the active principles of the wastes. In fact, chlorine treatment of the water supply, which is in almost universal use as an adjunct to water filtration, apparently serves to accentuate rather than to diminish the objectionable taste. After application of chlorine, in the minute quantities ordinarily used in treatment of public water supplies, the tastes have been noticeable in dilutions as great as one part of the wastes to ten million parts of water. Treatment of these wastes, to be effective, must, therefore, be most complete. Fortunately, such method of disposal is now available and consists, simply, in excluding all such wastes from streams used as sources of public water supply.

At the coke ovens, all of the objectionable and taste producing liquid wastes are collected arid used for quenching or cooling the glowing coke drawn from the ovens, thus passing into the air in clouds of steam. As an excess of the water is sprayed over the coke at a high rate, a portion is not evaporated at once, but passes through the coke into sumps beneath the quenching platforms and is recirculated by pumps to be evaporated during quenching subsequent charges of coke. Incidentally, the finely divided coke, formerly carried into the streams and lost with the excess quenching water, is now deposited in these sumps and salvaged, representing a saving which offsets the additional cost of operation of the circulating pumps. At the largest by-product coke oven installation in Pennsylvania the volume of contaminated water thus turned into steam is in excess of one million gallons daily.

At the gas manufacturing plants equally effective methods of disposal are in vogue. Waste waters from the gas washing chambers are freed from their burden of suspended tars and oils by passage through sedimentation and skimming tanks and the effluent water is recirculated through the process to again extract 
oil and tar from the gas. The oil and tarry deposits in these tanks form the base for the road oils so widely used on our highways and represent a considerable income to the owners of the works. At one of our large Pennsylvania plants where operation methods did not permit of constant recirculation of the water and would at times have permitted excess waste water to pass to the river, thus reducing the effectiveness of the entire treatment process, the difficulty was remedied by using this excess water in the plant boilers, after it had been modified by sedimentation and coagulation, followed by filtration through coke strainers and sand filters. As this gas company purchases boiler water from the city system, and as the labor cost at the sand filter is nominal, the saving in the water bills is gratifying to officials of the plant.

Other wastes productive of much trouble are those from oil refineries and from oil wells. The installation of settling basins provided with skimming weirs have been of value in separating oil from the wastes from refineries and form a source of considerable profit to the owners. In certain oil producing districts large volumes of salt water are pumped to the surface with the oil, and this is particularly true when the oil wells are nearing exhaustion. The salt water discharged into the streams, after removal of the oil, causes salinity sometimes almost equaling that of the ocean. The remedy to date in Pennsylvania has been simple and effective, consisting merely of the discharge of the salt water back into the well outside the pump casing, thus preventing stream pollution and using the salt water as a medium for bringing more oil to the surface.

A form of stream pollution which formerly caused much complaint in certain portions of the great iron industry districts was due to the discharge of the so-called "acid-iron" or "pickling" liquors-that is, the waste from the process of acid cleaning of rust and scale from metal, prior to tin plating, galvanizing or other surface treatment of plates or tubes. When the strength of the acid had been reduced to such a degree that it was no longer effective for rapid removal of rust and scale it was the practice to discharge it into the streams, which caused destruction of fish life and also rendered the water unfit for drinking by livestock in the pastures or for boiler or other manufacturing purposes. These wastes consist principally of ferrous sulphate, with some free sulphuric acid and ferric sulphate. They are now evaporated in 
acid-proof tubs, in the presence of iron turnings to neutralize the free acid and to reduce the ferric to ferrous sulphate, producing the crystalline ferrous sulphate of commerce. This procedure entirely prevents the discharge of waste acid from the pickling process, thereby abating the stream pollution.

Another interesting feature of waste disposal occurs in one of the branches of this general industry, the tin plate mills, where large quantities of palm oil and ordinary grain middlings are used in cleaning and polishing the tin plate. The palm oil has nutritive value, and as much of it is absorbed and retained by the middlings during the cleaning process, they are not discarded but are returned to the grain dealers and sold as cattle food. The mill owners simply pay what amounts to a rental charge for use of the middlings.

The most serious and extensive source of stream pollution in Pennsylvania is that due to the discharge of coal mine drainage, both from the anthracite and from the bituminous fields. The total volume of this waste is enormous. It has been estimated that over $850,000,000$ gallons of water are pumped from mines in the anthracite fields each day, and that the volume pumped or flowing from mines in the bituminous regions of the State approximates $600,000,000$ gallons daily. The total volume of this mine waste is about four times the volume of water furnished each day by the Philadelphia city waterworks.

The total quantity of free acid and acid salts carried by these mine wastes and by the discharge from the washeries has been estimated at over 3000 tons each day. It is impossible to even roughly estimate the total damage caused each year by this mine drainage, but recounting some of the havoc caused will serve to emphasize the seriousness of this pollution. The deposit on the stream beds of the fine coal carried by the mine drainage obstructs the normal flow channels, causing blockage of sewer outlets and increasing flood damage during high water periods. The sediment and the acid reaction destroy fish life. The increased hardness of the stream water is materially adding to the difficulty and expense of maintenance of at least ninety-six public waterworks in the State, supplying water to over 3,775 ,ooo people, or nearly 45 per cent. of our total population. The increased cost to navigation, to industry, to municipalities and to individuals in the Pittsburgh district alone, has been placed at over $\$ 8,000,000$ annually. The difficulties incident to control of this drainage are apparent 
when we consider that, exclusive of many small wagon mines, there are in the neighborhood of twenty-six hundred active mines in Pennsylvania, and, furthermore, that discharge of mine drainage is not restricted to active mines, but also occurs by water continuing to flow from abandoned mines and by rain water falling upon the great culm and waste piles carrying acid drainage and fine material into the streams.

Mine drainage is not by any means uniform in chemical composition nor in physical appearance. The acid content varies widely in different districts and even from mines in relatively close proximity. Another striking difference is that the water of mine drainage polluted streams in the bituminous regions is relatively clear in appearance and ranges from a light yellow to a reddish brown in color, whereas the streams of the anthracite region carrying drainage from the mines, the breakers and the coal washeries are black and opaque in appearance, due to the great quantities of finely divided coal which they carry.

No exact figures are available for the tonnage of this coal which has been discharged into the streams flowing from the anthracite regions. It is possible, however, to derive approximate figures which are startling. The excess in coal taken from the ground over that marketed during the last sixty years has been estimated to be more than 500,000,000 tons. This excess was either allowed to escape into the streams or was placed in great storage or culm banks near the mines. As the contents of these culm banks is believed to have been approximately 125,000,000 tons, we are forced to consider that the difference between these figures, or $375,000,000$ tons, represents the quantity of coal which has escaped into the streams from the mine fields.

Fortunately this enormous wastage does not represent a complete economic loss, for much of this coal has been deposited on the beds and along the banks of the streams and reclaiming operations have been practised for years along the Susquehanna, the Schuylkill, the Lehigh and their tributaries. The prevailing method for reclaiming the coal along the main streams is by small suction dredges, which pump a mixture of sand, coal and water from the bed of the stream. The discharge of the pump is over a screen, having six or eight meshes to the inch, and which serves to restrain the marketable coal while the finest particles of coal and much of the sand pass through the screen and are wasted. The

Vor. I01, No. II $46-58$ 
cost of reclaiming and marketing this " river coal," as it is called, is moderate, and it is much in demand, not only for use in large industrial boiler plants but in private homes. The shortage in freshly mined coal during the past three years has served to greatly increase the recovery of river coal and figures recently made public by the State Topographic and Geological Survey indicate that a total of about 2,000,000 tons were reclaimed from our streams during 1920 .

The increased cost of mining coal and the profits accruing from the simple dredging operations just described are causing the mine operators to realize that the coal now wasted by the wet process breakers and by the washeries should no longer be discharged into the streams. Furthermore, the need for some method of treatment whereby mine water can be successfully used in the breakers, obviating the great expense of pumping non-acid water long distances or the present high replacement costs due to the corrosive action of acid water, is each year becoming more apparent. A general idea of the volume of water required at the one hundred or more anthracite breakers can be obtained when we consider that approximately one gallon of wash water is required a minute for each one ton of the daily coal output, and the damage due to use of acid waters in the breakers may be estimated from the statement that annual replacement and repair costs of twenty thousand dollars at a single large breaker are not unusual.

Within the past two years several plants designed to eliminate the present coal wastage have been installed in the anthracite region. The process is, essentially, separation of the fine coal by sedimentation and can be further developed by neutralization of the acid by lime treatment to render the mine water suitable for use in the breakers. The sedimentation tanks are of the radial flow type, and the effluent is discharged over a weir around the periphery. Slowly revolving, radial arms sweep the sedimented particles to a small discharge opening at the apex of the inverted cone forming the bottom. The fine coal thus removed from the basins is passed through mechanical concentrators or classifiers, similar to those in use in lead, zinc and copper mining. Operating results at one of these coal recovery plants will serve as an illustration of the general process. Slush, after being wasted by the finest screen of a modern wet process mine breaker, a screen having holes threesixty-fourths of an inch in diameter, passes through the recovery 
plant at a rate of about 3500 gallons a minute and yields approximately 150 tons of usable coal a day. The effluent of this particular sedimentation basin is freed of materials which would be retained on screens having sixty meshes to the lineal inch, or approximately one-half the total weight of suspended solids in the breaker slush. Other basins are designed and operated to remove all solids which would be retained on a one-hundred-mesh screen. If desired, the wastes from the first set of basins and the concentrating tables can be passed through secondary basins for removal of all readily settleable materials, producing a clear effluent. It should be stated, however, that materials removed by such supplementary sedimentation would be mostly silt and particles of coal too fine for present market purposes.

It has been estimated that universal installation of settling basins of the type described, or others similar in function, would increase the coal output of the anthracite region by about 3,000,000 tons annually. Such increase would not only represent substantial profits to the mine owners, but, to a very considerable degree, would reduce the conspicuous and damaging stream pollution of these regions.

A generation ago the development of this method of freeing breaker and washery wastes from the fine particles of coal in suspension would have had little value, for there would have been no market for the salvaged coal. The combustion engineers who developed practical methods for using powdered coal as a fuel, successful procedure for briquetting coal and improved design of mechanical stokers have paved the way for this process of coal conservation.

For the neutralization of the acid mine drainage to permit its use in the breakers of the anthracite region and for quenching coke in the bituminous fields, we can turn to a method in successful and profitable use in the western part of the State. A few years ago at one of the coke burning villages the supply of neutral water for quenching purposes was insufficient during droughts, and as all the streams in the vicinity were so contaminated with mine drainage that use of the water would discolor the coke and increase its sulphur content, thus materially decreasing its market value, the engineers and chemists of the mining company undertook the neutralization of the acid stream water with limestone to produce a 
suitable water for use at the coke ovens, thus conserving the meagre supply of non-acid water in the reservoirs for domestic and power purposes.

These experiments have resulted in a plant which is treating upwards of one million gallons of mine water a day by addition of finely powdered limestone to neutralize the free sulphuric acid and to decompose the ferric sulphate into ferric hydrate. The sludge thus formed is removed by a sedimentation basin, similar to that described for removal of fine coal from drainage of the anthracite regions, and is then freed of excess moisture by a steam heated revolving dryer. The effluent water is sufficiently low in sulphur and iron to use for quenching coke and by virtue of the process the ovens at this mine have been operated during dry seasons when other mines in the vicinity were handicapped by a shortage of water. The dried sludge from the basins, containing ferric oxide, amounts to about seven tons a day and is in constant demand by manufacturers of artificial gas for use in removing the hydrogen sulphide present in such gas. It is stated that the revenue from this plant is materially in excess of the operating cost, thus furnishing the company with an additional water supply of approximately one million gallons a day at little or no expense. Experiments are now under way for a further development of this by-product, for example, as a substitute for the iron oxide in paint pigments and utilization of the phosphorus and potassium constituents in soil fertilization.

Even though feasible and profitable methods have been developed for removing the fine coal from the wastes of the anthracite region and for neutralization of the free acid of the wastes of both the anthracite and bituminous regions, we have not by any means solved the mine drainage problem. The enormous quantities of lime which would be required for neutralization of the acidity of drainage from all of the mines, together with the moderate market for the resulting product place limitations upon the wide adoption of this method. Furthermore, it is faulty in one essential feature, the effluent is not freed of the incrusting constituents and hence is not suitable for either boiler or domestic water supply purposes, even after passage through fine grained sand filters. It has previously been stated that some ninety-six water supplies of the State are now difficult of purification because of mine drainage pollution of the raw water, and this number is certain to grow as addi- 
tional mines are opened, contaminating streams now free from acid drainage and increasing the contamination of streams at present receiving only moderate volumes of such drainage.

The most successful method yet devised for neutralization of acid mine drainage and for removal of the boiler scale forming constituents makes use of barium carbonate, which reacting on the sulphates formed by previous addition of lime, results in the relatively insoluble barium sulphate, which can be removed by filtration, giving a clear and soft water. At least three such plants are in operation in the west and are stated to produce a superior water for boiler purposes. Unfortunately, the barium salts are expensive and, of more consequence, they are poisonous. There is no absolute guarantee that the barium will always be entirely precipitated when used in treatment of a water contaminated by a combination of mine drainage with other wastes which are acid in reaction, especially in the event of accidental and unforeseen conditions of filter plant operation. Its use, therefore, for treatment of water intended for human consumption cannot be justified.

The absence of a satisfactory method for complete treatment of mine drainage is not because the problem has been neglected by able investigators, but rather is due to the fact that, in the past, studies have been directed at only a single aspect of the problem, and when the particular objective had been reached the search was abandoned.

This is equally true in the case of other industrial wastes; for instance, there have been studies to develop methods of treatment of certain wastes to prevent nuisance in the case of discharge into a large body of water, other studies to prevent destruction of fish life, and numerous others simply to recover single products of value which had been wasted.

Within the past few years various government departments and bureaus and the scientific staffs of large industrial establishments throughout the world have undertaken comprehensive studies of methods of disposal of many industrial wastes. The object of these studies has been two-fold: first, to recover products of value from the wastes, and second, in case such products did not exist or could not be extracted by any method known to science, to develop some economical process for modifying the wastes so as not to prevent any legitimate uses of the receiving body of water and to determine the limitations of the method of disposal selected. 
Only since the inception of this class of investigations has real and definite progress been made.

The industrial prosperity of any State may safely be said to depend upon a suitable and adequate water supply. With the tendency to concentration of our industries, the local needs for such water supplies will increase, requiring even greater progress to be made in solution of industrial waste disposal problems. Investigations made thus far demonstrate that the goal can be reached only through refined methods of manufacture to make use of all possible elements of value in the raw materials and also methods of treatment which will recover all products of commercial value in the industrial wastes in order to partially or even wholly offset the cost of treatment of the portions which are without value.

Progress towards this end has been rapid and the future is bright. Therefore, it appears that the creation of nuisance in streams and the destruction of their usefulness through lack of proper disposal of industrial wastes has passed the peak, and that in a few years such improvements in the general condition of the surface waters of our industrial states will be obtained that they can be economically used for all legitimate purposes.

Action of Sodium Sulphide on Ferric Oxide.-By the reaction of finely divided ferric oxide with crystalline sodium sulphide, a black amorphous substance is formed. After the major portion of the sodium sulphide has been removed, the residual mass yields a brilliant green solution; the color is due to a colloidal iron compound which contains neither sodium nor sulphur in its molecule. The colloid is precipitated by a relatively large amount of sodium sulphide, also by complete removal of the sodium sulphide by either dialysis or oxidation. The green solution contains less than 0.07 gram iron per litre, and cannot be dialyzed in the presence of air. If air be drawn through the solution until the sodium sulphide is oxidized to sodium sulphate, the color of the solution changes to brown, apparently due to the formation of a colloidal hyclrated ferric oxide which finally precipitates. (J. C. WItT in Journ. Am. Chem. Soc., I92 I, xliii, 734-740.) 